\title{
Implications and Characterization of Waste Glass Cullet - Kaolinite Clay Ceramics
}

\author{
1,3,*ABUH, MA; ${ }^{2}$ AGULANNA, CA; ${ }^{1,4}$ CHIMEZIE, PE; ${ }^{5}$ BETHEL-WALI, JU \\ ${ }^{1}$ Department of Ceramics Engineering Research and Production, Projects Development Institute (PRODA), Enugu State, Nigeria \\ ${ }^{2}$ Department of Materials and Energy Technology, Projects Development Institute (PRODA), Enugu State, Nigeria \\ ${ }^{3}$ Department of Chemical Engineering, Enugu state University of Science and Technology (ESUT), Enugu State, Nigeria \\ ${ }^{4}$ Department of Chemistry, University of Nigeria $(U N N)$, Nsukka, Enugu state, Nigeria \\ ${ }^{5}$ Department of Space and Application Research, National Space Research and Development Agency (NASRDA - ASTAL), Uyo, Akwa-Ibom \\ State, Nigeria \\ *Corresponding Author Email: markabuh1@gmail.com
}

\begin{abstract}
Cullet(x) reinforced ceramics $(100-\mathrm{x})$ made from Ukpor kaolinite clay by dry-pressing and fired at temperatures $\left(\mathrm{T}^{0} \mathrm{C}\right)$ for $900 \geq \mathrm{T} \leq 1250^{\circ} \mathrm{C}$ with $0 \leq \mathrm{x} \leq 40 \%$ wt was investigated for its ceramics application. The chemical profile of the samples (cullet and clay) was determined by Atomic Absorption Spectroscopy (A.A.S) technique. Mineral composition was determined by XRD while SEM was employed to view the phase modification. The particle size of the raw materials was maintained at $<180 \mu \mathrm{m}$. The mechanical properties, micro-structure, and phase composition are discussed with respect to cullet content and temperature variation. It was observed that production temperature decreased with increase in cullet. Micro-structural study showed a granulated morphology and the formation of phase-boundary as granules fuse due to clay cullet crystallization with increase in cullet and temperature. Electrical insulation is greatly improved while thermal insulation is reduced due to the closure of pores with increase in cullet and temperature respectively. The mechanical properties of flexural strength, porosity, bulk and apparent density, shrinkage and water absorption were greatly modified for every $10 \%$ increase in cullet content. Production temperature greatly reduced with increase in cullet suggesting longer lifespan for the kilns and furnaces used. The study supports the utilization of cullet in the production of ceramics, a good reason to recycle waste to wealth but in excess of $20 \%$ cullet, production temperature must not exceed $1100^{\circ} \mathrm{C}$ due to development of cracks.
\end{abstract}

\section{DOI:https://dx.doi.org/10.4314/jasem.v23i3.22}

Copyright: Copyright $\left({ }^{\circ}\right.$ 2019Abuh et al. This is an open access article distributed under the Creative Commons Attribution License (CCL), which permits unrestricted use, distribution, and reproduction in any medium, provided the original work is properly cited.

Dates: Received: 30 January 2019; Revised: 19 February 2019; Accepted 22 March 2019

Keywords: Bulk Density, cullet; porcelain; porosity; Ukpor clay (U.C); temperature

Glass is essentially a transparent material produced when materials such as silica, soda ash, feldspar, $\mathrm{CaCO}_{3}$ and other fluxes are mixed, melted at high temperature, blown into different shapes and sizes then cooled to solidify without crystallizing. More than $25 \%$ of urban waste generated is glass. Cullet is a name given to waste glass which has been crushed into different particle sizes ranging from coarse aggregates to very fine powder depending on the intended use. These wastes come from pharmaceutical packaging, installations for domestic and industrial works, and the beverage companies accounting for the highest. Ceramics is an alternative for utilizing this waste. More than $95 \%$ of all manufactured glass is made from sodium oxide, calcium oxide and silicon dioxide, commonly referred to as soda-lime-silica composition. Cullet is commonly used as additive in glass reforming due to its low softening temperature (Furlani et al, 2010). Cullet constitutes serious nuisance to the environment, a burden to humans since it is inert, nonbiodegradable and very difficult to dispose as it can remain active in a dumpsite for a thousand years.
Cullet is used as road construction aggregate, asphalt paving, concrete aggregate, and building, applications (glass tiles \& bricks, wall panels' e.t.c). fibre glass insulation, glass fibre, abrasive, art glass, Agricultural fertilizers, landscaping, reflective beads tableware, hydraulic cement among other applications (Shayan, 2002; Rindl, 1998). The absence of regulations in the disposal of these glass wastes has led to the indiscriminate dumping on just anywhere in the environment. Since raw-materials for the production of new glass ware/ bottles are cheap, there is no worthwhile attempt at recycling or reuse of the glass waste or their retrieval from the environment for proper treatment before disposal. The addition of glass has been found to reduce firing temperature and time resulting in an increase in production capacity (Tyrell and Goode, 1972). It has been shown that these new ceramics (clay - cullet) can be formed with higher density, higher hardness, lower drying shrinkage, less water absorption and other good physical qualities (Sahar et al, 2011; Ioryuenyong et al, 2009). There is no reported attempt at using cullet as a component of 
a recipe for ceramics body formulation in Nigeria. This work focuses on the implications and effects of addition of glass cullet of particle size $<180 \mu \mathrm{m}$ in the production of low to mid temperature ceramics from very commonly used Nigerian kaolinite clay (Ukpor Clay). The engineering properties and micro-structural modification of the cullet reinforced ceramics products were studied for optimal application.

\section{MATERIALS AND METHODS}

Preparations of raw material: The waste glass was obtained from pharmaceutical stores, restaurants and eateries, alcoholic beverage bars and dumpsites. The papers and plastic labels on the waste bottles were removed; bottles were then washed with water and detergent to remove all oily or greasy contaminants, earths and organic impurities. The washed bottles were air dried and then oven dried at $110^{\circ} \mathrm{C}$. The dried waste glass was then charged into a high-energy ball milling machine with twice its volume of water and milled continuously for $72 \mathrm{hrs}$ to obtain very fine particles. The resulting slurry was poured out and allowed to separate under gravity. The resulting liquid was poured out; the fine glass which settled under gravity was obtained, dried at $110^{\circ} \mathrm{C} \pm 5^{\circ} \mathrm{C}$ to constant weight. The caked cullet obtained was further pulverized again then sieved using a 200 mesh BS sieve. The same process was applied in processing the U.C used as described (Abuh et al, 2014).
Specimen Preparation: Test specimens used were prepared by mixing the raw clay, U.C (100) and cullet $(X)$ to form the ceramic body $(100-X)$ at $X=0$, 10, 20, 30 40. Temperature, $\mathrm{T}\left({ }^{\circ} \mathrm{C}\right)$ of $900=\mathrm{T} \leq 1250$ was used. Each batch of specimen was manually mixed to homogeneity as described by Pena $e t a l$, (2016). Calculated amounts of water was then added and mixed vigorously followed by wedging to achieve mouldability for the body. The plastic paste obtained was Casted into rectangular, cylindrical and spherical metallic moulds as reported (Abuh et al, 2014).

Tests Method: The Chemical profile of cullet and U.C was evaluated using AAS. The physical tests were carried out as described (Abuh et al, 2014) before firing and after firing at the experimental temperatures. The micro structural analyses were carried out as described (Pena et al, 2013) using SEM Philips XL-30 ESEM. The XRD pattern was measured according to method described by Oluseyi et al (2013), using Philips diffractometer Model PW 1730. Mineral peaks were identified using XPert High Score plus Software.

\section{RESULTS AND DISCUSSION}

The chemical profile of the raw materials are shown in table 1 and compared in Fig 1 . The cullet belongs to the soda-lime- silica glass which contains very high amount of $\mathrm{SiO}_{2}, \mathrm{CaO}$ and $\mathrm{Na}_{2} \mathrm{O}$.

Table 1. Chemical profile of the raw materials used

\begin{tabular}{lllllllllll}
\hline & \multicolumn{10}{c}{ Composition by \% } \\
\hline & $\mathrm{SiO} 2$ & $\mathrm{~A} 12 \mathrm{O} 3$ & $\mathrm{Fe} 2 \mathrm{O} 3$ & $\mathrm{CaO}$ & $\mathrm{K} 20$ & $\mathrm{~T} 1 \mathrm{O} 2$ & $\mathrm{LOI}$ & $\mathrm{MgO}$ & $\mathrm{Na} 2 \mathrm{O}$ & Refractoriness \\
Cullet & 71.13 & 1.39 & 0.16 & 10.62 & 0.03 & 0.08 & 0.00 & 0.83 & 14.18 & \\
Ukpor Clay & 49.26 & 33.28 & 1.17 & 0.58 & 2.51 & 0.53 & 12.23 & 0.14 & 1.2 & $>16000 \mathrm{C}$ \\
\hline
\end{tabular}

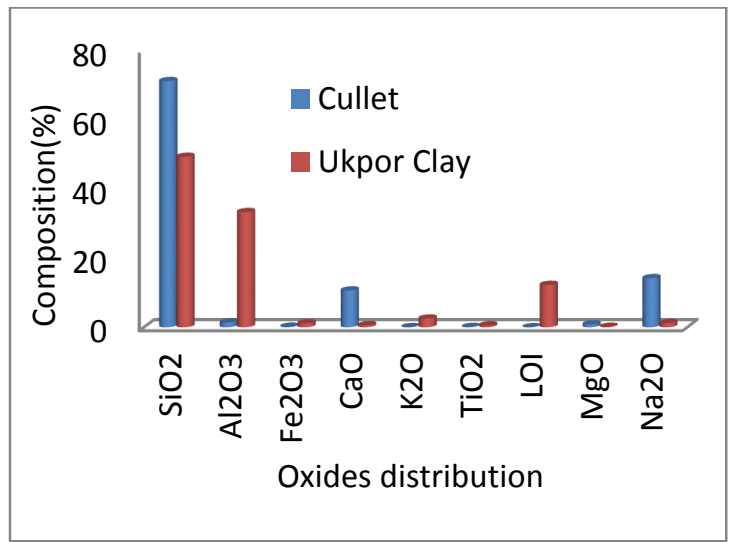

Fig 1: Oxides distribution profile in cullet and ukpor kaoline clay.

The presence of $\mathrm{Na}_{2} \mathrm{O}$ (Alkaline oxide) and $\mathrm{CaO}$ (Alkaline earth oxide) in the cullet composition is indication of strong fluxing oxides which are incorporated into the body recipe to pull down the vitrification temperature of silica and glass forming materials and with increase in cullet content, these oxides are indirectly increased. $\mathrm{Na}_{2} \mathrm{O}$ is a primary low temperature flux which is normally introduced through the addition of Borax $\left(\mathrm{Na}_{2} \mathrm{O} .2 \mathrm{~B}_{2} \mathrm{O}_{5} .10 \mathrm{H}_{2} \mathrm{O}\right)$ or soda ash $\left(\mathrm{Na}_{2} \mathrm{CO}_{3}\right)$ to the body recipe. The $\mathrm{CaO}$ also a secondary mid-temperature flux is always introduced through the addition of lime also called whiting $\left(\mathrm{CaCO}_{3}\right)$, calspar also called anorthite $\left(\mathrm{CaO} . \mathrm{Al}_{2} \mathrm{O}_{3} .4 \mathrm{SiO}_{2}\right)$ or Dolomite $\left(\mathrm{MgCO}_{3} \cdot \mathrm{CaCO}_{3}\right)$ to the recipe during formulation. The $\mathrm{Fe}_{2} \mathrm{O}_{3}$ content of Ukpor Clay was found to be $<2 \%$ which was why the clay fired white. Values of $\mathrm{Fe}_{2} \mathrm{O}_{3}$ $>2 \%$ implies clay will change colour depending on the percentage involved (Singer and Singer, 1993; Gupta, 2008). This low value amongst other parameters 
accounts for the high utilization of Ukpor Clay in the electrical insulators production.

Mechanical Characterization of Cullet Reinforced Ceramics Products: Linear Shrinkage: The shrinkage increased with increase in temperature and cullet as shown in Fig 2.

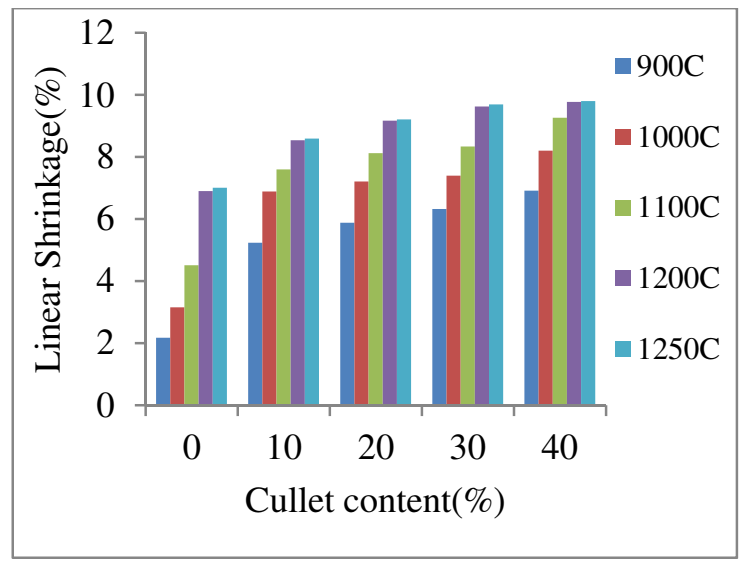

Fig 2: Shrinkage response profile to Cullet and Temperature

The high composition of quartz in the cullet as shown in fig 1 may reduce linear shrinkage due to the strength of the $\mathrm{Si}-\mathrm{O}$ bond. But increasing cullet also means increasing the fluxing oxides and reduction in vitrification temperature. As the cullet content $(\%)$ increased, the linear shrinkage (\%) increased. This is due to replacement of kaoline in the clay with cullet which flow at high temperatures creating holes. Thermal compression forces particles together in the matrix increasing the shrinkage. Cracks were visible at $1200^{\circ} \mathrm{C}$ for $\mathrm{G} 3$ (30\% cullet) and G4 (40\% cullet) discouraging cullet use in excess of $20 \%$. This also suggests the need to produce at temperatures $\leq 1100^{\circ} \mathrm{C}$.

Apparent Porosity: The profile as shown in Fig 3 shows a decrease in porosity with increase in cullet and temperature respectively. Porosity alone would have encouraged higher utilizatin of cullet as values tend to zero with increase in temperature but the cracks also increase above $20 \%$ cullet. To avoid cracks, temperatures $\leq 1100^{\circ} \mathrm{C}$ are recommended. Values obtained for $10 \%$ and $20 \%$ at $1000^{\circ} \mathrm{C}$ and $1100^{\circ} \mathrm{C}$ were lower than those obtained for $0 \%$ at $1250^{\circ} \mathrm{C}$ as shown in fig 3 . At cullet of $\leq 20 \%$, values obtained at $\mathrm{T}\left({ }^{0} \mathrm{C}\right)$ $\leq 900^{\circ} \mathrm{C}$ were comparable with ceramics produced at temperature $(\mathrm{T}) \geq 1300^{\circ} \mathrm{C}$ without cullet reinforcement.

Water Absorption: Water absorption decreased with increase in temperature and cullet respectively as shown fig 4.

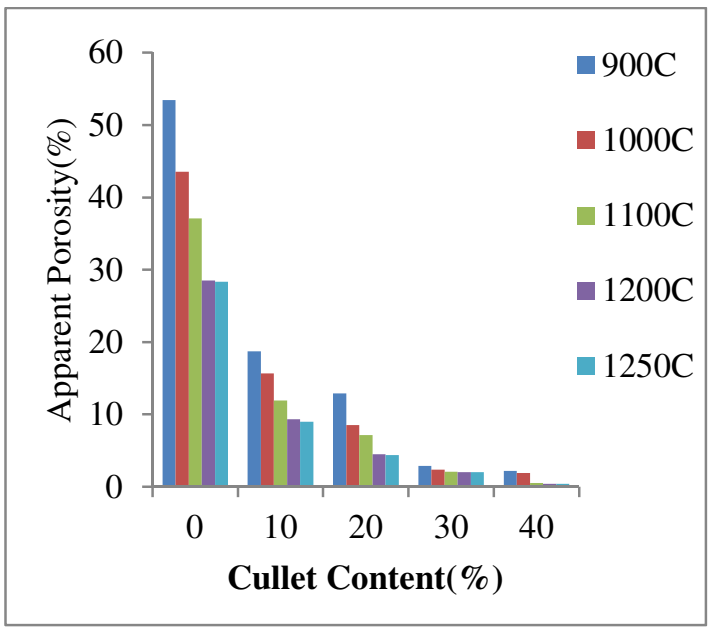

Fig 3: Apparent porosity response profile

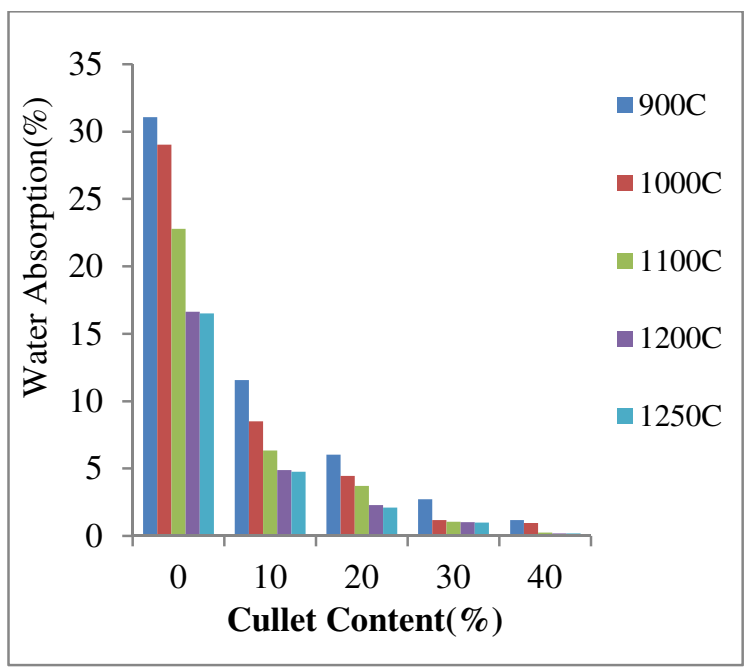

Fig 4: Water absorption response to cullet profile

The value obtained at $20 \%$ cullet at $1200^{\circ} \mathrm{C}$ being $2.3 \%$ was within the recommended value of $2.6-2.7 \%$ (Chester, 1973). At lower temperatures of $900^{\circ}-$ $1000^{\circ} \mathrm{C}$ values obtained for $\mathrm{X} \geq 30$ were within the chester recommended limits. Water absorption increased with increase in temperature and cullet respectively as shown in fig 4 . If lower temperatures are intended, cullet in excess of $20 \%$ is recommended for production of low density insulations, bricks, tiles, and other ceramics applications which normally require temperatures $\mathrm{T} \geq 1100^{\circ} \mathrm{C}$ for production. But if higher temperatures are prefer, then $\mathrm{X} \leq 20 \%$ is recommended to avoid cracking.

Bulk Density: The plot for the B.D is shown in fig 5. The figure shows an increase in B.D with increase in cullet and temperature respectively. The increase in B.D signifies increase in compaction and closure of pore (Ituma et al, 2018; Abuh et al, 2018). 


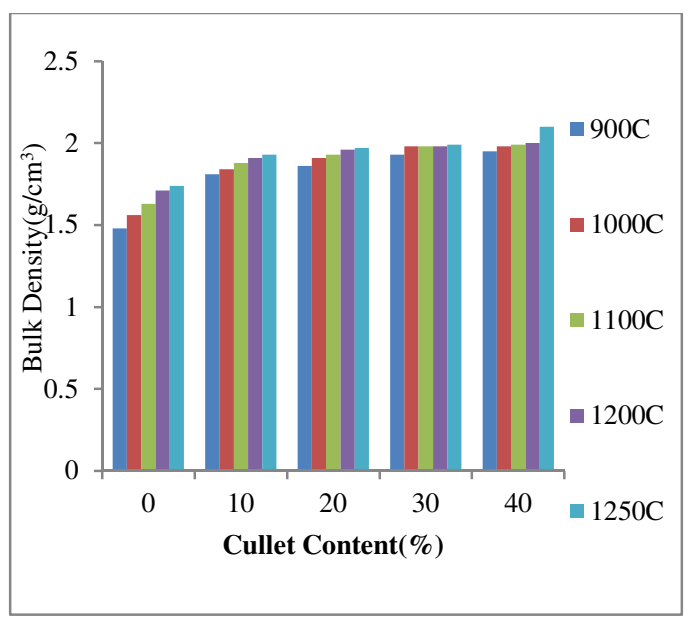

Fig 5: Bulk density against cullet profile

The higher the cullet content, the higher the bulk density. Higher cullet content increased the fluxing oxides in the body which forces the quartz and kaoline content of the body to melt and flow even at midtemperatures. This flow tends to fill and seal up all spaces created and consequently increases the bulk density. The higher the cullet, the higher the fluxing oxides accumulation in the body and the lower the vitrification temperature. Higher cullet content and temperature $\leq 1100^{\circ} \mathrm{C}$ was suitable but above this temperature, cracks were visible. This implies lower cullet content at high temperature or high cullet content at temperatures $\leq 1100^{\circ} \mathrm{C}$ is recommended. Values obtained were higher than $1.74 \mathrm{~g} / \mathrm{cm}^{3}$ observed for the pure clay at $1250^{\circ} \mathrm{C}$.

Apparent Density: A.D decreased with increase in cullet content. The response of A.D to increase in cullet and temperature is shown in fig 6 .

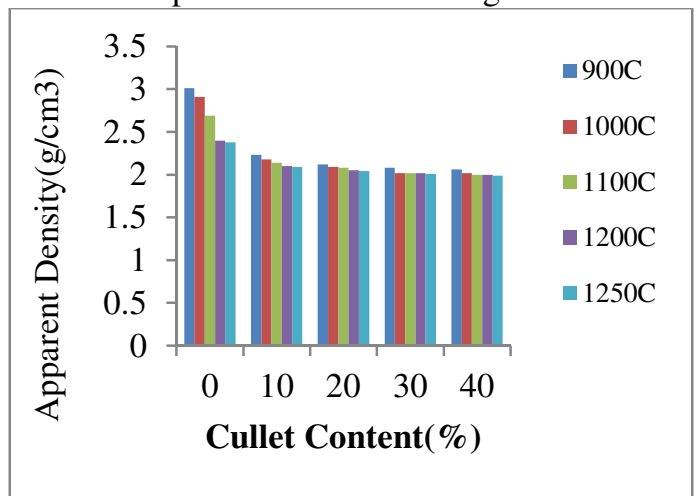

Fig 6: Apparent density against cullet profile

The plot shows a decrease in A.D with increase in temperature and cullet. As pores are closed up due to formation of glass in the matrix, the A.D decreases as shown in fig 6. The smaller the value for A.D, the higher the extent of compaction. Value obtained for $0 \%$ cullet at $1250^{\circ} \mathrm{C}$ was higher than that obtained for
$10 \%$ cullet and $20 \%$ cullet at $1000-1100^{\circ} \mathrm{C}$ which implies higher compaction for the cullet reinforced samples at lower temperatures.

Flexural Strength: With increase in cullet, the plasticity is lost due to loss of surface water or physisorbed water and dehydroxylation of clay respectively and homogenous interaction is broken as clay particles are forced apart weakening the strength. When temperature increases, the strength of the ceramics increases shown in fig 7. The strength of ceramics wares is influenced by the chemical and mineralogical compositions of the raw materials, the heating temperature of production, the rate of heating, the soaking time of firing, and the kiln atmosphere (reduction or oxidation).

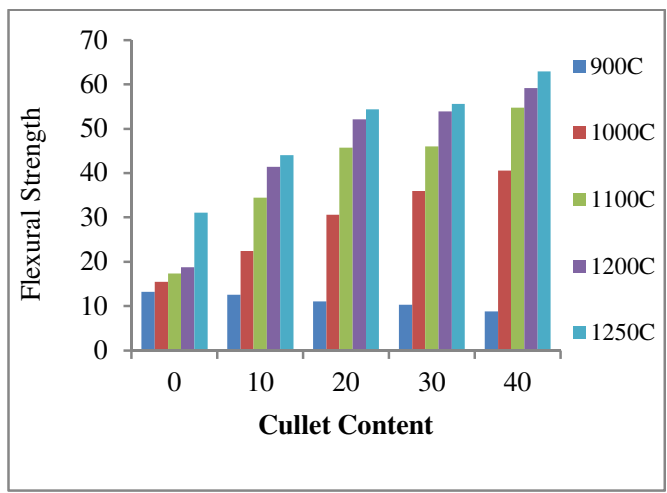

Fig 7: Response of Flexural Strength to cullet profile

The increase in strength with increase in temperature may be due to interaction of the oxides producing mullite and free silica in the form of cristobalite (Abuh et al, 2018; Anih, 2005)

$3 \mathrm{Al}_{3} \mathrm{O}_{2}+6 \mathrm{SiO}_{3} \rightarrow 3 \mathrm{Al}_{2} \mathrm{O}_{3} \cdot \mathrm{H}_{2} \mathrm{O}+4 \mathrm{SiO}_{2}$

(Alumina) (Silica) (Mullite) Crystoballite)

The silica content is increased with increase in cullet which is melted at high temperatures by interacting oxides to produce soda lime glass which confers hardness when cooled to ambient conditions. Increasing the cullet tends to increase the amount of free silica present which melts with increase in temperature to form a uniform dense structure that greatly confers strength on the body. Value of $31.2 \mathrm{kgF} / \mathrm{cm}^{2}$ at $1250^{\circ} \mathrm{C}$ for the pure clay ( $0 \%$ cullet) was lower than $34.47 \mathrm{kgF} / \mathrm{cm}^{2}$ and $45.72 \mathrm{~kg} / \mathrm{cm}^{2}$ obtained for $10 \%$ cullet and $20 \%$ cullet respectively at $1000^{\circ} \mathrm{C}$ which suggest the utilization of cullet to increase the strength of ceramics materials at low temperatures without recourse to high temperatures for same outcome, saving energy, materials, time and equipment life cycle. 
Refractoriness: this thermal resistance property of the ceramics $(100-\mathrm{X})$ was greatly affected by variation in the cullet $(\mathrm{X})$ content. The higher the cullet content, the lower the refractoriness. Increasing the cullet increases the proportion of fluxing oxides such as $\mathrm{CaO}, \mathrm{MgO}, \mathrm{K}_{2} \mathrm{O}$ and $\mathrm{Na}_{2} \mathrm{O}$ which acts on the $\mathrm{Si}-\mathrm{O}$, $\mathrm{Al}-\mathrm{O}$ and $\mathrm{Al}-\mathrm{Si}$ bonding. The interaction of these oxides with $\mathrm{Si}$ and $\mathrm{Al}$ in the ceramics matrix $(100-\mathrm{X})$ at red heat pulls down the vitrification temperature of the body to a temperature too low for refractory applications (Abuh et al, 2018). Values obtained clearly shows that Cullet reinforced ceramic is not suitable for refractory applications. Reinforced ceramic bodies suitable for refractory must have refractoriness of $\geq 1500^{\circ} \mathrm{C}$ (buh et al, 2018; Ituma et al, 2018). Values obtained for the ceramics $(100-\mathrm{X})$ were well below the stated limit.

Cold Crushing Strength: CCS measures the maximum load per unit area that a product will withstand before failure occurs at ambient temperature under specified conditions and compression. Value obtained at $900^{\circ} \mathrm{C}$ was $>1500 \mathrm{KN} / \mathrm{M}^{2}$ for all the reinforced samples. Though at $900^{\circ} \mathrm{C}$, this parameter was not discriminatory, it is still not advisable to consider refractory or high temperature applications for the cullet reinforced materials in excess of $20 \%$. However, above $20 \%$ but at temperatures below $1000^{\circ} \mathrm{C}$ this shows good resistance to abrasion and CCS. This means that the resistance to abrasion will be within requirements for suggested applications. There is however a high tendency for CCS to decrease with increase in cullet and temperature. This suggests the low utilization of cullet at high temperatures or high utilization at low temperature if CCS and resistance to abrasion are factors. The higher the cold crushing strength, the higher the resistance to abrasion and vice versa [Abuh et al, 2018]. The resistance to slag attack will also be below the standard for refractory, electrical and thermal insulation and other high temperatures ceramics application since the higher the CCS of materials, the higher the resistance to slag attack (Abuh et al, 2018).

XRD Analysis: Fig $8[\mathrm{G}]$ shows that the cullet is predominantly quartz $\left(\alpha-\mathrm{SiO}_{2}\right)$.This result shows that the raw materials and by implication the final product would contain more $\mathrm{SiO}_{2}$ (Quartz) than any other mineral. $\{\mathrm{H}]$ confirms that the clay is Kaolinite with quarts existing as the other component.
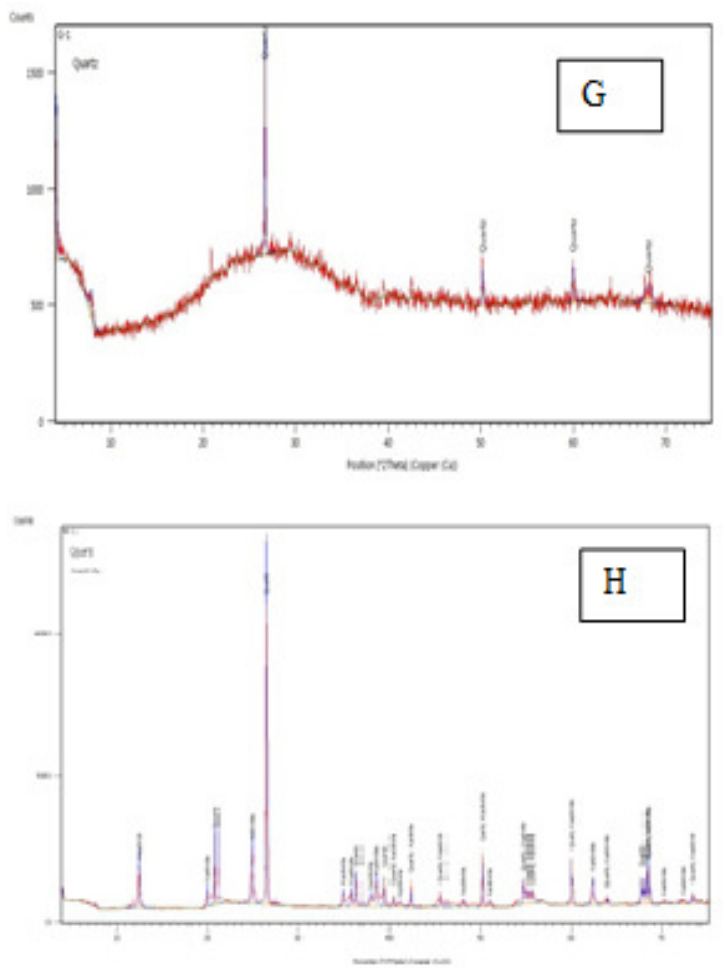

Fig 8: XRD pattern of; [G] ceramic with $40 \%$ cullet at $1200^{\circ} \mathrm{C}[\mathrm{H}]$ Ukpor Clay

SEM Analysis:Figure $9[\mathrm{I}]$ shows well defined uniform crystals in the cullet structure. Figure 9 [J] shows poorly distributed non-uniform grains and presence of numerous clay minerals and inorganic impurities in the body and Figure $9[\mathrm{~K}]$ Contains $40 \%$ cullet and shows increase in the crystalline process although more cullet would be needed if all the phases are to be completely embedded in the ceramic matrix. A closer observation of the surface morphology shows that increase in cullet increases the tendency of a uniformly distributed grains, high contact surface and consequently, decrease in porosity and water absorption. 

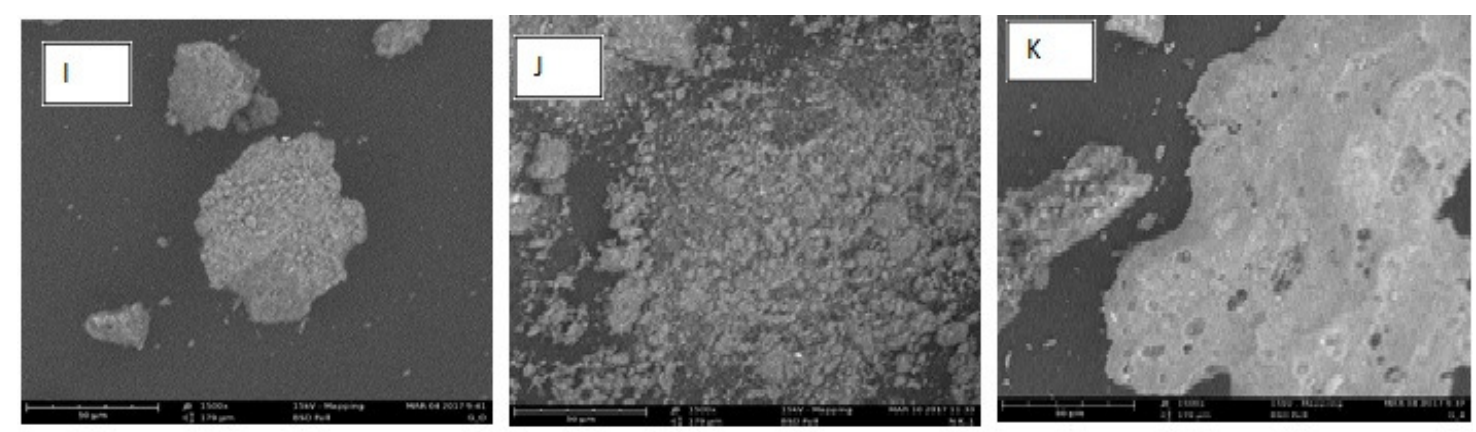

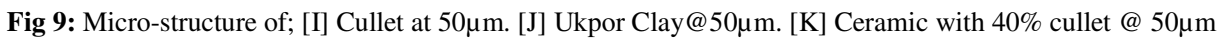

CONCLUSIONS: Cullet is mostly Silica and Alumina with very strong fluxing oxides such as $\mathrm{Na}_{2} \mathrm{O}$ and $\mathrm{CaO}$ which interferes with its use in insulator bodies' beyond $20 \%$ due to visible cracks, zero porosity and a tendency to flow at elevated temperatures. Mechanical properties obtained at very high temperatures $\left(\geq 1200^{\circ} \mathrm{C}\right)$ can be obtained at temperature $\leq 1100^{\circ} \mathrm{C}$ with the addition of cullet at varying proportions. The suggested use of cullet is limited to $<20 \%$ for high temperatures $\left(\mathrm{T} \geq 1200^{\circ} \mathrm{C}\right)$ and above $20 \%$ for lower temperatures $\left(\leq 1000^{\circ} \mathrm{C}\right)$. Reinforcement of clay bodies with cullet helps to reduce production temperature, improve mechanical properties of the final products, reduces production time, increases the lifecycle of the production equipment, and reduces the energy requirements.

\section{REFERENCES}

Abuh, MA; Abia-Bassey, N; Udeinya. TC; Nwannewuihe. HU; Abong. AA; Akpomie. KG (2014). Industrial Potentials of Adiabo Clay in Calabar Municipal of Cross River State, SouthSouth Nigeria. Pacific J. Sci. Technol. 15(1):63-75.

Abuh, MA; Idenyi, NE; Etukudoh, AB; Ituma, CG; Obioha, CI; Asadu, CO. (2018). Ceramics application of Mgbom Clay: Characterisation and micro-structural studies. Leonardo Elec. J. Prac. Technol. 33; $105-122$.

Anih, LU (2005). Indigenous manufacture and characterization of electrical porcelain insulators, Nig. J. Technol. 24 (1). $1-7$.

Chester, JH (1973). Refractories, Production and Properties. The iron and steel institute, 3-13, 295314.

Furlani, E; Tonello, G; Maschio, S (2010). Recycling of steel slag and glass cullet from energy saving lamps by fast firing production of ceramics, Waste Management; vol.30, no.8-9, pp.1714-1719
Gupta, OP (2008). Elements of Fuels Furnace and Refractories" $5^{\text {th }}$ Edition, second reprint, Khanna Publishers, New Delhi

Ituma, CG; Etukudoh, AB; Abuh, MA; Akpomie, KG; Obioha CI (2018). Utilization of NkpumaAkpatakpa clay in ceramics: characterization and microstructural studies, J. Appl. Sci. Environ. Manage. 22 (1), p. 47-53.

Loryuenyong, V; Panyachai,T; Kaewsimork K; Siritai,C (2009). Effects of recycled glass substitution on the physical and mechanical properties of clay bricks, Waste Manage. .29. 10. 2717-2721.

Oluseyi, AK; Atul. M; Das, SK (2013). Effect of Substitution of Soda-Lime Scrap Glass for KFeldspar in Triaxial Porcelain Ceramic Mix, INTERCERAM - REFRACTORIES MANUAL II: $299-303$.

Peña, PP; Lozano, MAG; Pulido AR; Castro, RHL; Jurado Z; Quiñones, V; PérezMedina, JC; Vázquez MEP; Torres, AV (2016). Effect of Crushed Glass Cullet Sizes on Physical and Mechanical Properties of Red Clay Bricks, Hindawi Publishing Corporation Advances in Materials Science and Engineering Volume, Article ID 2842969, 5 pages

RINDL, J (1998). Report by Recycling Manager, Dane County, Dept of Public Works, August, Madison; USA

Sahar, MR; Hamzah,K; Rohani,MS; Samah, KA; Razi, MM (2011). The Micro-structural Study of CulletClay Ceramics, International Conference on Physics Science and Technology (ICPST 2011), Physics Procedia 22; 125 - 129

Shayan, A (2002). IABSE SYMPOSIUM MELBOURNE Singer, F; Singer, S (1993). Industrial Ceramic, London Chapman and Hill Limited. Pp. 234.

Tyrell, ME; Goode, AH (1972). Waste Glass as a Flux for Brick Clays; Report of Investigations 770 In Bureau of Mines. 